\title{
Jon Anderson
}

\section{Exiled on Mountain, Bewail Fate \& Praise Autumn}

Now that I'm actually living my solitude I'm clueless. Every now \& then the wind drops in \& I look at it. These are the signs of seasonal change: I'm not sweating, $\&$ the hollow of air in the chimney makes a thrumming noise. The doves outside my house look like they're waiting at a bus stop \& puff into little black \& grey pots when the wind blows or when the rain comes down in columns. Now that it's quiet in my house I can't really think without thinking \& I can't really talk without meaning something else, so I shut up. Some days I wish I was back at the factory, moving heavy objects \& grunting.

They start out looking for a handout, then get used to it, the birds. What's weird is I think they don't know why they come anymore now that I've stopped feeding them. Frankly, they tend to be undifferentiated \& cutely stupid. Once, when one fell off the wall, I thought I had something, it was so embarrassed, lying there like a ruffled pompom with a black tack for a head. Turned out it was dead. I was so alienated I mailed it back without a stamp, but I said this prayer for it: Bless every living thing. . . .

I didn't mean to exclude it.

Shortly afterward I was bombed by a traveling flock of chickadees fresh from a meeting on a rotten stump. When you're alone every damn word you say has got to be how you feel, \& then you've got to live with it. I think I'll entertain myself by not experiencing anything. Word on the mountain is that the wabi of consciousness is all your living minus all your accumulated experience. That's why the chickadees attacked, because I'd blown it. 